\title{
An accurate pattern classification for empty fruit bunch (EFB) based on the age profile of oil palm tree using neural network
}

\author{
Wafi Aziz', 'Afif Kasno², Nurkamilia Kamarudin³ , Zaidi Tumari', Shahrieel Aras', \\ Herdy Rusnandi ${ }^{6}$, Kamal Musa \\ ${ }^{1,2,4}$ Centre for Robotics \& Industrial Automation (CeRIA), Faculty of Engineering Technology, \\ Universiti Teknikal Malaysia Melaka, Malaysia \\ 3,6,7 Faculty of Engineering Technology, Universiti Teknikal Malaysia Melaka, Malaysia \\ ${ }^{5}$ CeRIA, Faculty of Electrical Engineering, Universiti Teknikal Malaysia Melaka, Malaysia
}

\section{Article Info \\ Article history: \\ Received Jan 11, 2019 \\ Revised Jul 23, 2019 \\ Accepted Jul 30, 2019 \\ Keywords: \\ Empty fruit bunches Image processing \\ Neural network}

\begin{abstract}
This paper proposes an efficient method for pattern classification system of empty fruit bunch (EFB) by using a neural network technique. The main advantage of this method is the accuracy and speed of algorithm such that it can be computed rapidly with the proposed system. To test the effectiveness of the proposed method, 120 of EFB's data with different ages and length that been obtained from Malaysian Palm Oil Board (MPOB) are use in the pattern classification process. In addition, there are three classes of EFB in this system, which are Class 1 (less than 7 year old), Class 2 (8 to 17 year old) and Class 3 (more than 17 year old). It is envisaged that the proposed method is very useful in classifying the EFB and $90 \%$ of the sample parameters are successfully classified to its class.
\end{abstract}

Copyright () 2019 Institute of Advanced Engineering and Science. All rights reserved.

\section{Corresponding Author:}

Ab Wafi Bin Ab Aziz,

Faculty of Engineering Technology,

Universiti Teknikal Malaysia Melaka,

75300 Durian Tunggal, Melaka, Malaysia.

Email:wafi@utem.edu.my

\section{INTRODUCTION}

In 2017, Malaysia had 5.81 million hectares of planted area with oil palm trees [1]. The crop normally bears fruit within three years after planting in the field [2]. As a result, mixtures of FFB from different ages of oil palm trees were harvested, collected and transported to palm oil mills for processing. Apart from the production of palm oil, the mills also generate lignocellulosic residues that include empty fruit bunches (EFB) and mesocarp fibers (palm pressed fiber). Figure 1 illustrates the extraction of palm oil, starting from the FFB harvesting in the field to oil extraction at palm oil mill.

Based on the dry matter content, the amount of dry EFB would be 5.5 million tonnes per year. Hence the quantities at hand could make a very substantial contribution to the supply of raw materials for the production of biocomposite products that have traditionally been made of wood fibers [3]. Thus, the industry is actively looking for commercial outlets to eliminate possible pollution or disposal problems caused by these residues $[4,5]$. This will indirectly help to increase the value of EFB for the palm oil millers.

This paper presents a method to classify EFB based on its ages by using a neural network technique. There will be three classes in total which are Class 1, Class 2 and class 3. Detail for each class is shown in Table 1 . The age is being identified by measuring the length of EFB spikelet [6, 7]. This is done manually by MPOB employees. 


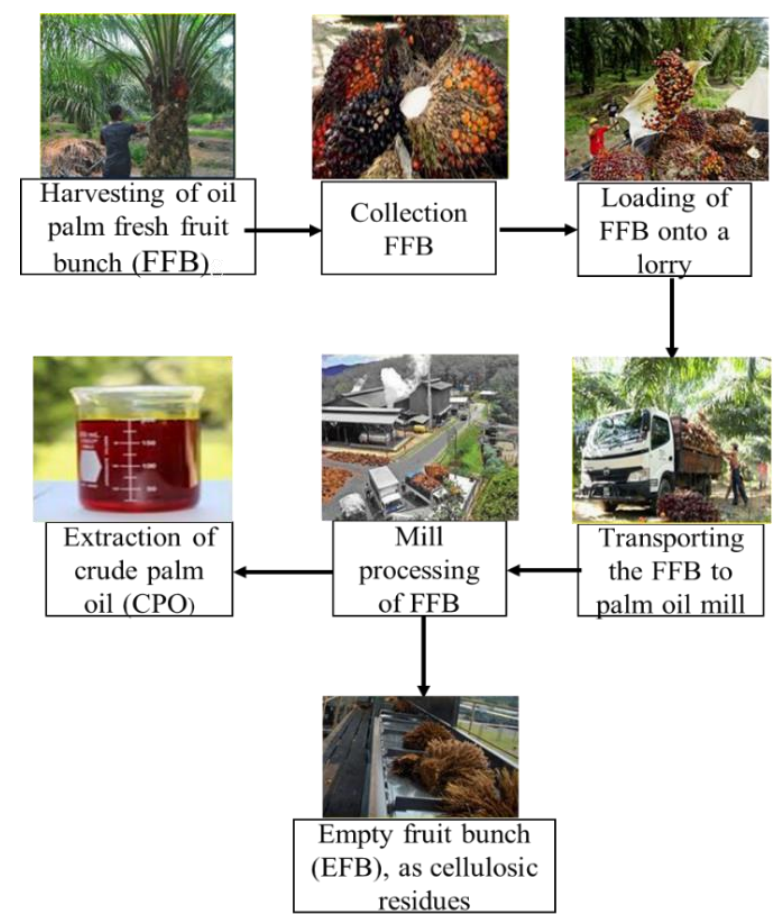

Figure 1. Palm oil process flow

Table 1. Class segregation

\begin{tabular}{|c|c|c|}
\hline Class & Years & Industries \\
\hline 1 & 2 to 7 & Mattress, Coir \\
\hline 2 & 8 to 17 & Soft board, Potting, Fibre mat \\
\hline 3 & 18 to 25 & Monetary notes \\
\hline
\end{tabular}

Figure 2 shows dried EFB where the rectangle represents EFB spikelet. The current utilization of the EFB is inefficient and has low productivity due to the age is not been determined after processes of an oil palm fruits extraction in the palm oil milling process. The EFB is said to be the final product achieved whereby it is available in abundance after the milling process of FFBsuccessfully done. The current practice does not has a good parameters to reuse the EFB for making goods to the industry. This is due to lack of economical system for handling and storage and less desirable quality of resulting products. By proposing the right method to classify the EFB, it will help the industry to determine the right quality of EFB for a specific application. A high quality of EFB can be sold at higher price subsequently generate additional income to oil palm industry.

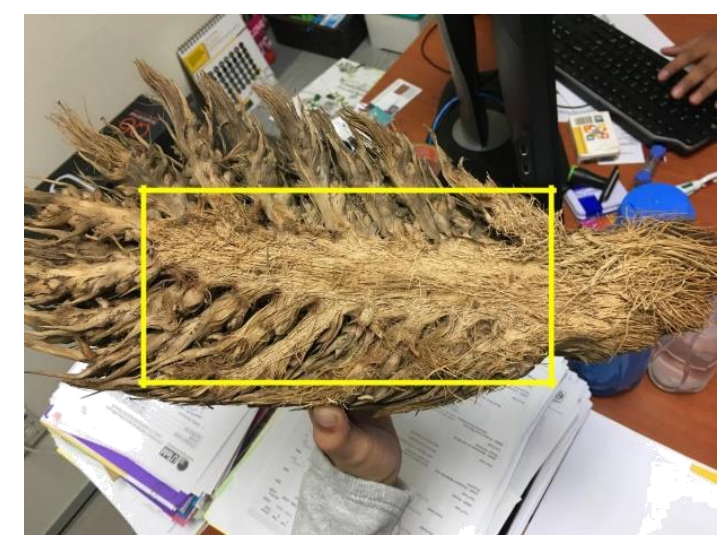

Figure 2. Empty oil pump fruit bunch (EFB) 
The objective of this paper work is to develop a method to classify the EFB based on it age classes by using neural network. Neural network has capability to analyze data especially when the data does not follow the same distribution pattern $[8,9]$. Arduino microcontroller is use to demonstrate the result from the neural network. Furthermore, if the objective achieved, the income of palm oil millers will be increased due to the increasing of EFB utilization in other industries. This is very crucial in the palm oil industry because classification of EFB by its ages have a good value for different manufacturing industries. The EFB can be sold based on its class age and the price will be higher compare to EFB that not been classified An example of products that can be made from the EFB are high quality printing paper, photographic paper, monetary notes, fibre mats, fibre-board, and soft board [10-12].

\section{RESEARCH METHODOLOGY}

\subsection{Neural network implementation}

The designing of the neural network is using MATLAB software. Figure 3 shows the flow chart for the neural network implementation. The data length of EFB spikelet given by MPOB was imported to MATLAB for training in the neural network. Learning Vector Quantization (LVQ) is chosen as the type of neural network in this research [13-21]. Since it is suitable to deal with a complex parameters where the operation can be implemented in supervised technique or unsupervised. By using the supervised technique, this method can reduce the number of misclassified since the variables will be reclustered according to class specification [22-24]. Figure 4 shows the network architecture for LVQ.

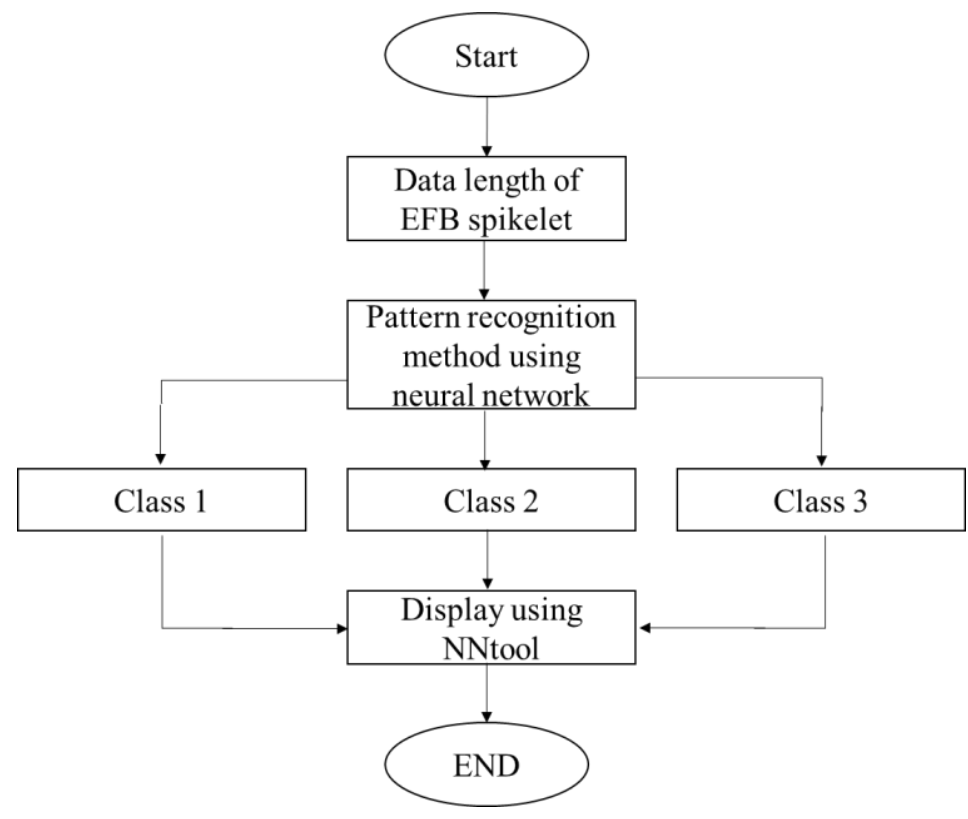

Figure 3. Flow chart of neural network implementation

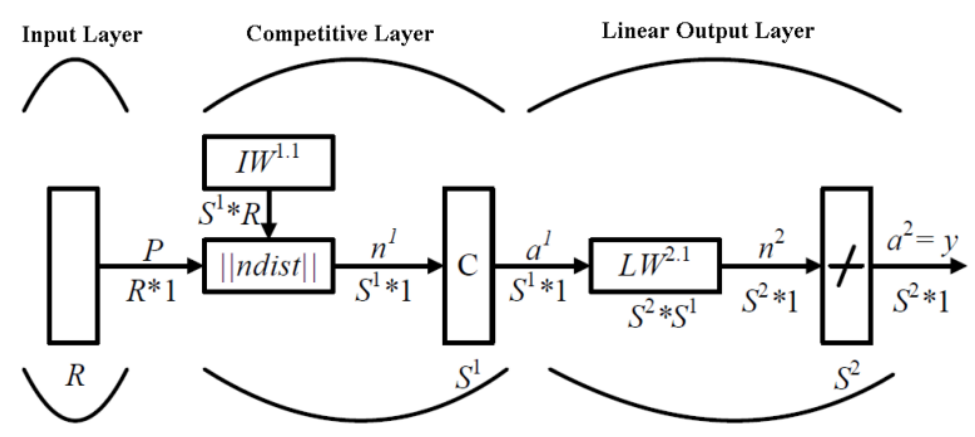

Figure 4. LVQ neural network architecture [10] 
For the setting of LVQ, a number of first-layer hidden neurons is set to 10 , the learning rate is set to $\left(\begin{array}{ll}0.33 & 0.33 \\ 0.34\end{array}\right)$ and no learning function is applied. In the algorithms setting, training is set to random weight/bias rule and performance is set to mean squared error (mse) [22]. The number of iterations is set to $1000[21,23,25]$. The code used for the neural network for this project is shown in (1). Figure 5 shows neural network layer system design using the Matlab software.

$$
\text { net }=\operatorname{newlvq}(\operatorname{minmax}(p), 10,[0.330 .330 .34])
$$

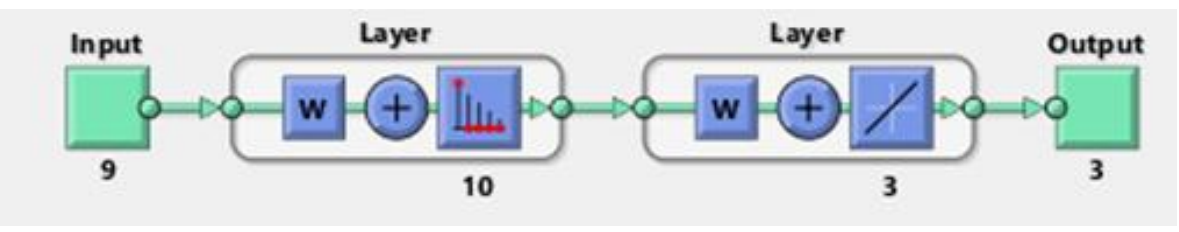

Figure 5. Neural network layer system

To monitor simulation of the process in Matlab, graphical user interface (GUI) is constructed as shown in Figure 6. It includes three phases which are input, processes and result.

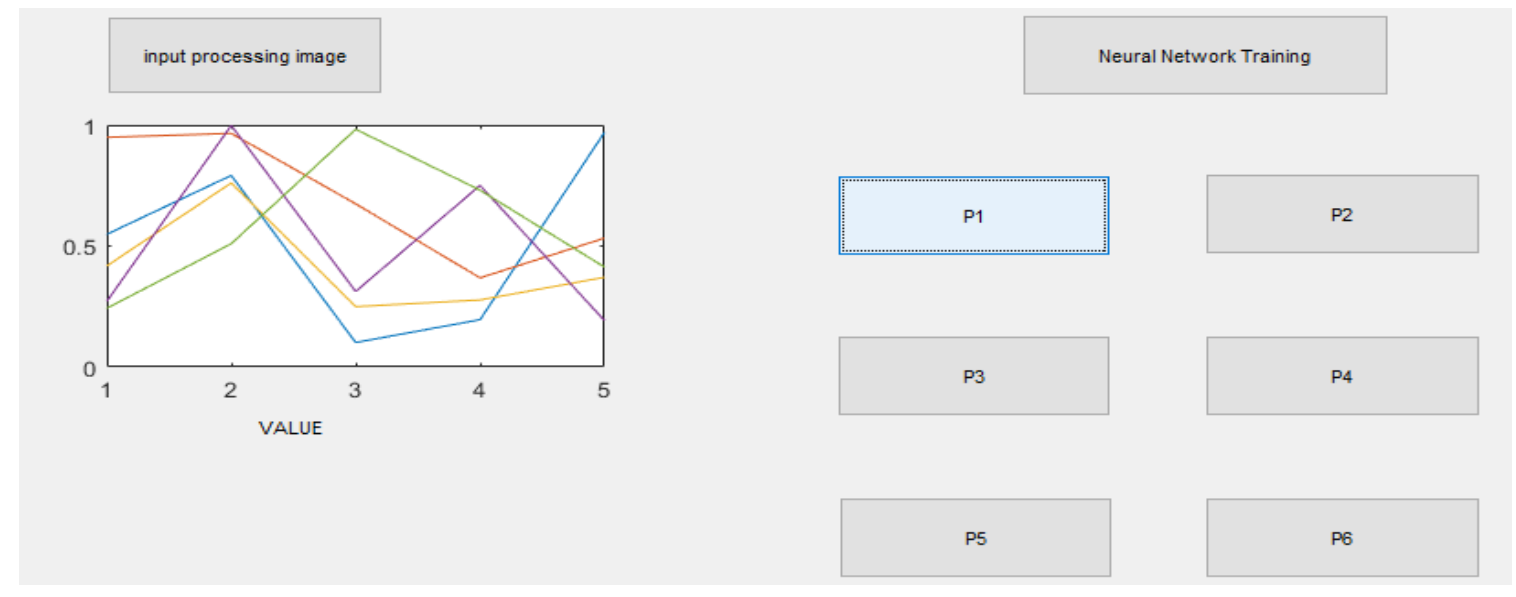

Figure 6. GUI for neural network

\subsection{Interface}

The purpose of hardware development is to show the results of the neural network classifier. This system can be used as a reference in order to recognise the class of EFB. Three LEDs are used to indicate the successful group age class in the neural network system. Moreover, an Arduino microcontroller is used to control the LEDs and as the linkage between MATLAB software via USB port. Yellow LED indicates that Class 1 is detected, red LED indicates Class 2 is detected and green LED indicates Class 3 is detected. Figure 7 shows the circuit diagram for the hardware interface.

Figure 8 shows a block diagram for the hardware interface. The Arduino is connected to laptop installed with MATLAB software via USB cable. MATLAB Support Package for Arduino is installed to enable communication between MATLAB and Arduino. Result obtained from the neural network is sent to Arduino. Yellow LED, red LED and green LED are used as the output indicator where each one of it represents Class 1, Class 2 and Class 3, respectively. 


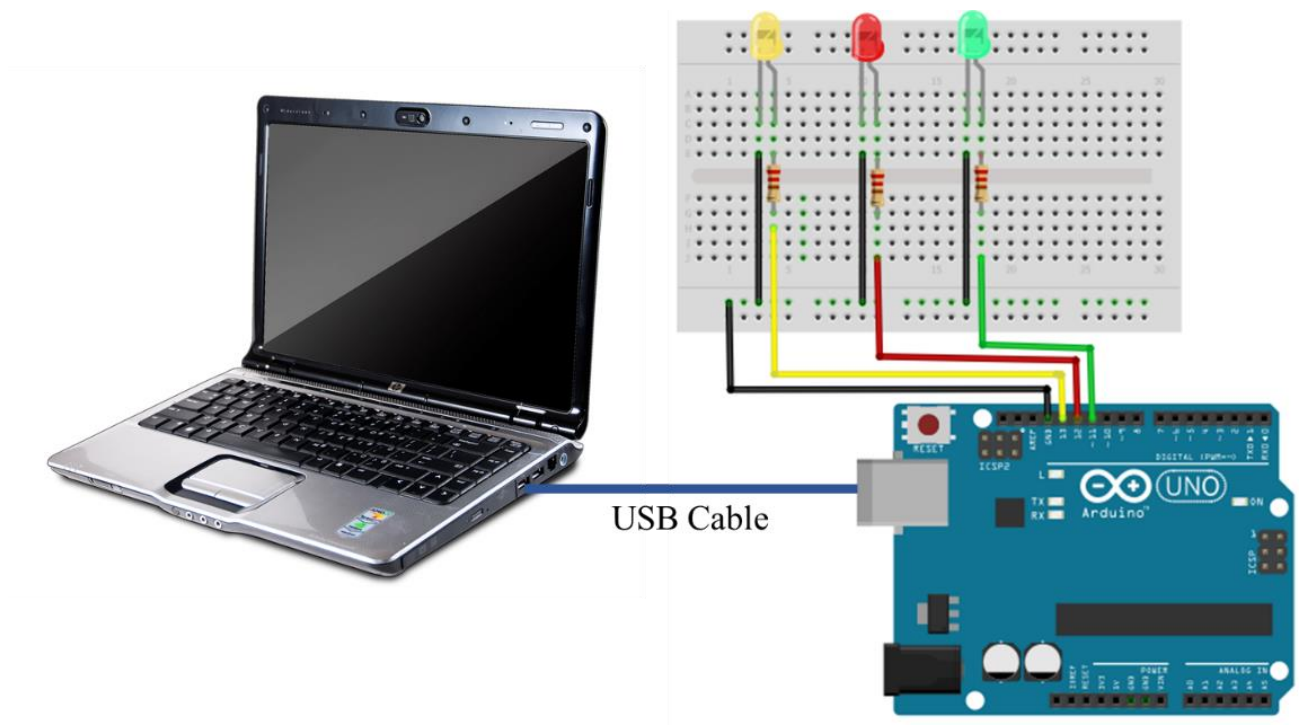

Figure 7. Hardware demonstration

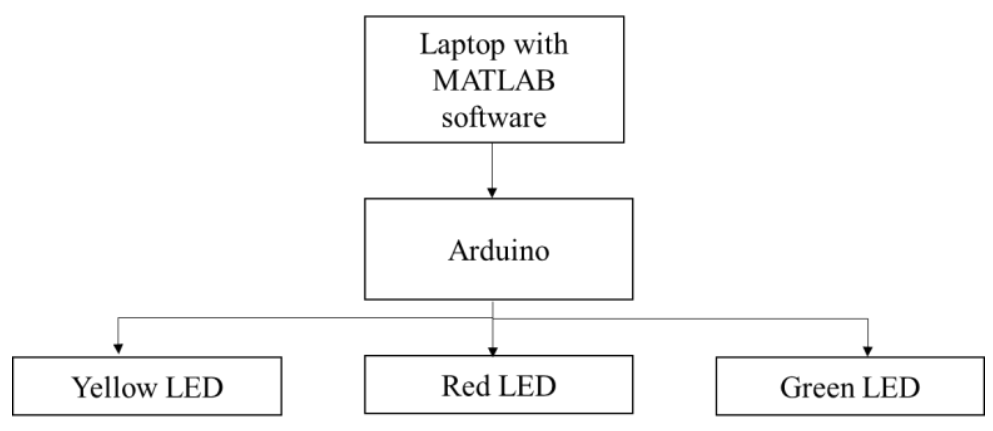

Figure 8 . Block diagram of hardware interface

\section{RESULTS AND ANALYSIS}

Figure 9 shows the progress of neural network training and the result is shown through nntools along with the training performance. The number of iteration can be classified if the neural network is a fast learner or slow learner whereas the lesser the number of iteration, the lesser time taken the machine to finish the training [26]. Figure 10 shows training performance graph of epoch versus mean squared error (MSE). From the graph, the best training performance is at epoch 14, which is 0.027778 mse. Means, after it reaches the epoch 14, the training performance became consistent due to pattern recognition already able to identify the pattern.

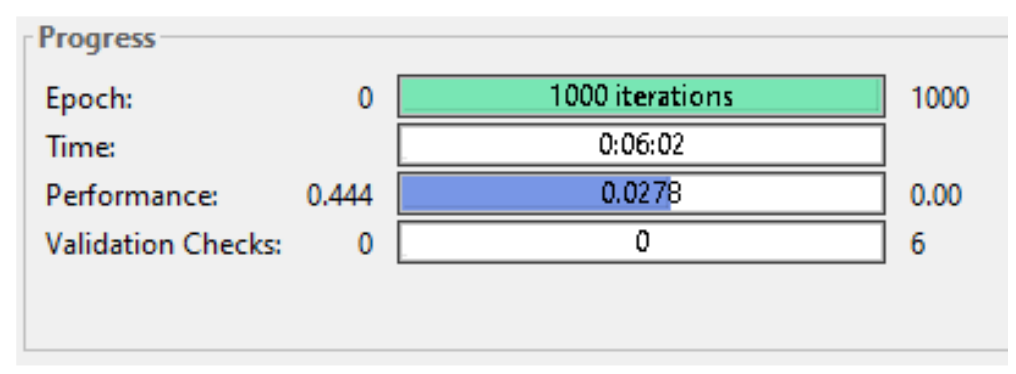

Figure 9. The progress of neural network training 


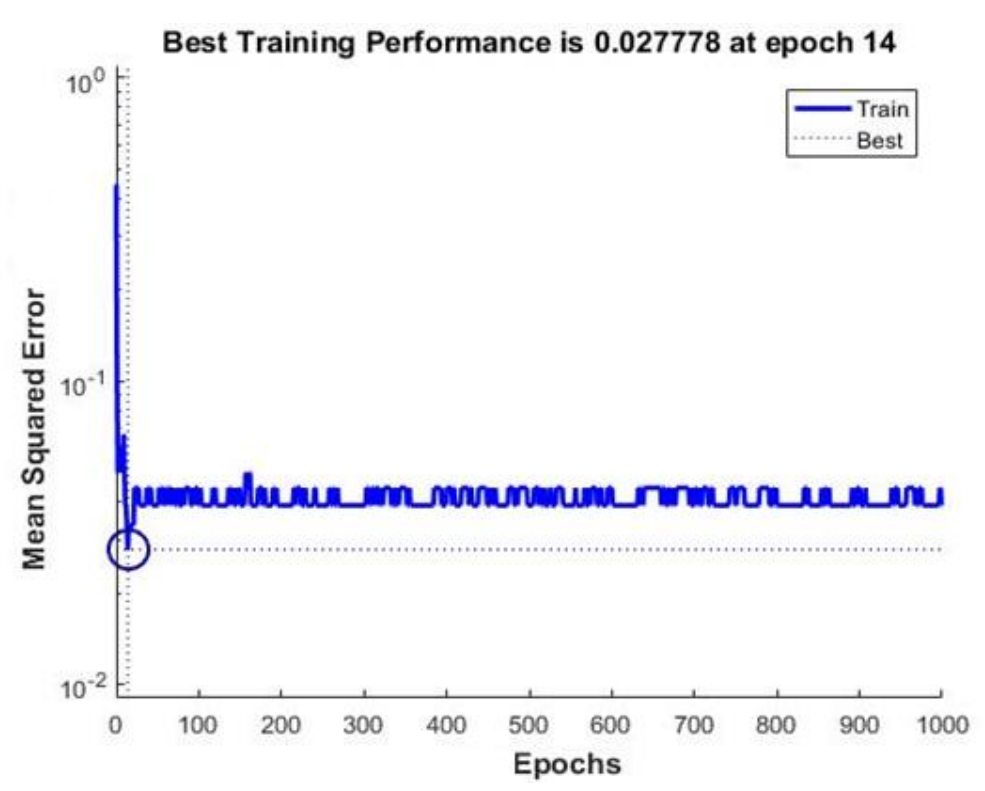

Figure 10. Training performance of epoch versus mse

Figure 11 demonstrates the confusion matrix for the training result. Green color shows the percentage and number of successful data output for each target class. Whereas the red color indicates the percentage and number of wrongly classification data. For target Class 1, 33 out of 40 data for Class 1 is successfully been classified which give $82.5 \%$ of successful rate. Remaining 7 data of Class 1 are wrongly classified into Class 2 and Class 3 where each of it has a number of 4 and 3 data respectively. The failure of the classification is due to the insufficient of data sample data and inconsistency value of the data Class 1 during the training of the neural network.

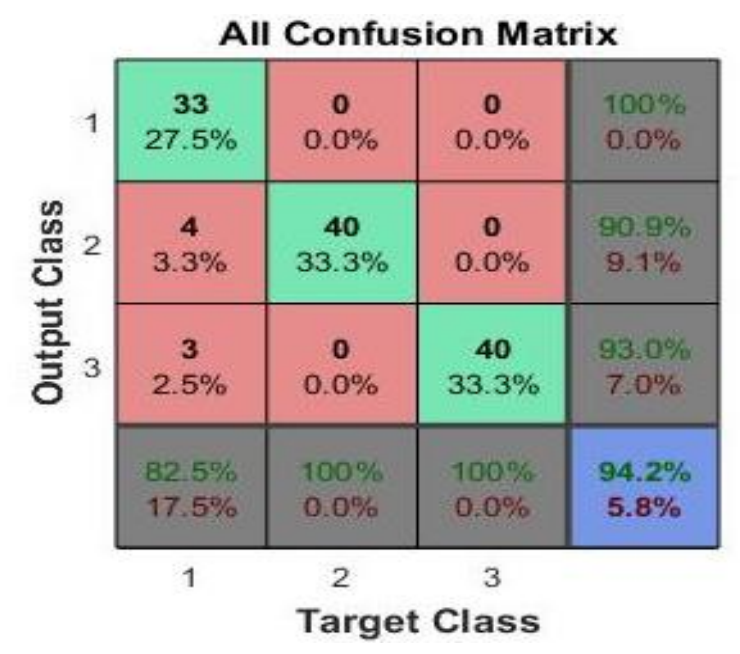

Figure 11. Table of confusion for output class

For Class 2, the successful rate of classification is $100 \%$ where all 40 data are successfully classified into Class 2. This achievement is continued by Class 3 where all data are also successful classified. The perfect classification for Class 2 and Class 3 is due to the consistency of sample data for both classes. Out of 120 sample data from all classes, the successful rate is $94.2 \%$. Table 2 summarizes the result of the simulation. 


\begin{tabular}{cccc}
\multicolumn{4}{c}{ Table 2. Summary of result } \\
\hline Target Class & $\begin{array}{c}\text { Successful data } \\
\text { detected }\end{array}$ & $\begin{array}{c}\text { Percentage per } \\
\text { target class }\end{array}$ & $\begin{array}{c}\text { Accuracy per target class } \\
\text { (out of 120 samples) }\end{array}$ \\
\hline 1 & 33 & $82.5 \%$ & $27.5 \%$ \\
2 & 40 & $100 \%$ & $33.3 \%$ \\
3 & 40 & $100 \%$ & $33.3 \%$ \\
& Total & & $94.2 \%$ \\
\hline
\end{tabular}

The receiver operating characteristic (ROC) is plotted to show the true positive rate. The percentage per target class is shown in Figure 12 below. Training $100 \%$ able to process, the validation is 0 as well as the test ROC is linear zero. The validation and positive rate are linear and this is clearly prove that no validation should is occured.
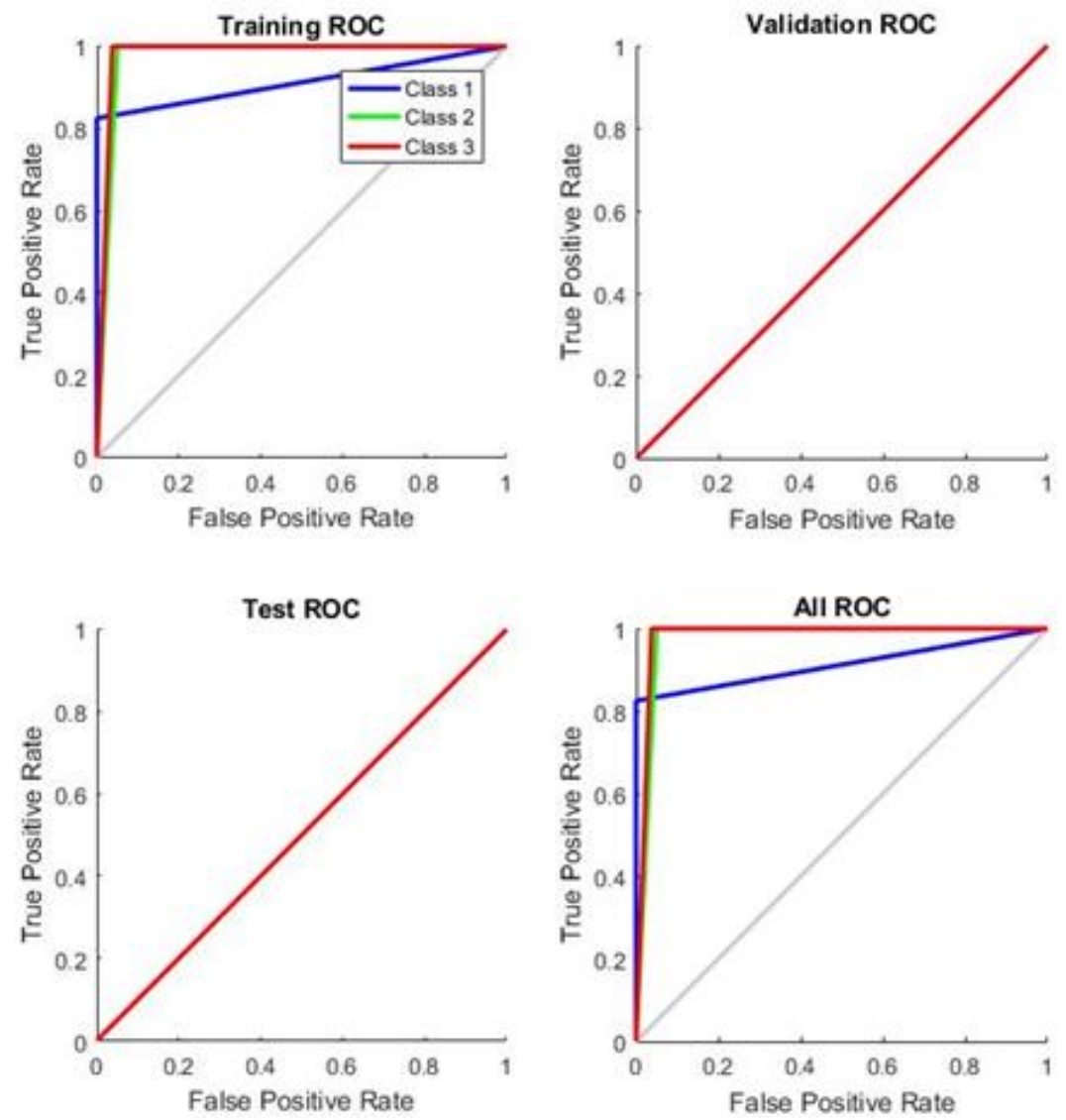

Figure 12. Receiver operating characteristic (ROC) result

\section{CONCLUSION}

The main objective of the proposed method is successfully achieved where the sample of EFB from different age groups are classified into its specified group by using a neural network. Furthermore, an image processing system is recommended for automatic measurement of the EFB's length.

\section{ACKNOWLEDGEMENTS}

The authors would like to thank UTeM for sponsoring this work under the short-term grant, UTeM, PJP/2017/FTK-CERIA/S01555. 


\section{REFERENCES}

[1] Malaysian Palm Oil Board 2018, "Overview of malaysian oil palm industry," 2018, [Online], Available: http://bepi.mpob.gov.my/index.php/en/.

[2] A. Kushairi, et al., "Chapter 3. Oil palm breeding and seed production," Furthern Advances in Oil Palm Research (2000 to 2010), MPOB, Bangi, vol. 1, pp. 47-101, 2011.

[3] H. Kamarudin, et al., "Oil palm fibres for medium density fibreboard: a classification of oil palm biomass for more uniform MDF-quality," Proceedings of the 8th Pacific Rim Bio-based Composites Symposium, Kuala Lumpur, Malaysia, pp. 30-41, 2006.

[4] A. Lewicki, et al., "Potential of Biogas Production from Palm Oil Empty Fruit Bunch (EFB) in South-East Asia," 2018 2nd International Conference on Green Energy and Applications (ICGEA), Singapore, 2018, pp. 1-4.

[5] N. N. Kasim, et al., "Demineralization of oil palm empty fruit bunch (EFB) intended as a high quality bio-oil feedstock," 4th IET Clean Energy and Technology Conference (CEAT 2016), Kuala Lumpur, 2016, pp. 1-6.

[6] P. B. Tomlinson and C. J. Quinn, "Palms do not undergo secondary stem lengthening: A response to Renninger and Phillips (American Journal of Botany 99: 607-613)," Am. J. Bot., vol. 100, pp. 461-464, 2013.

[7] M. Ninazunta, et al., "Growth strategies of the arborescent palm Iriartea deltoidea in a western Amazonian forest," Bot. J. Linn. Soc., vol. 182, pp. 411-424, 2016.

[8] Hendrawan Y., et al., "Image Analysis using Color Co-occurrence Matrix Textural Features for Predicting Nitrogen Content in Spinach," TELKOMNIKA Telecommunication Computing Electronics and Control, vol. 16(6), pp. 2712-2724, 2018 .

[9] V. Nedic, et al., "Comparison of Classical Statistical Methods and Artificial Neural Network in Traffic Noise Prediction," Environmental Impact Assessment Review, vol. 49, pp. 24-30, 2014.

[10] N. Abdullah and F. Sulaiman, "The Oil Palm Wastes in Malaysia," Biomass Now - Sustainable Growth and Use, Dr. Miodrag Darko Matovic (Ed.), InTech, 2013, [Online], Available: https://www.intechopen.com/books/biomassnow-sustainable-growth-and-use/the-oil-palm-wastes-in-malaysia

[11] Husin M., et al., "Research and Development of Oil Palm Biomass in Wood Based Industries," Malaysian Palm Oil Board Bulletin, Palm Oil Development, vol. 36, 2005.

[12] S. Sumanthi, et al., "Utilization of Oil Palm as a Source of Renewable Energy in Malaysia," Renewable and Sustainable Energy Reviews, vol. 12, pp. 2404-21, 2008.

[13] H. He, et al., "A Method for Identification of Driving Patterns in Hybrid Electric Vehicles Based on a LVQ Neural Network," Energies, pp. 3363-3380, 2012.

[14] P. Melin, et al., "A new neural network model based on the LVQ algorithm for multi-class classification of arrhythmias," Inf. Sci. (Ny)., vol. 279, pp. 483-497, 2014.

[15] K. J. Devi, et al., "Prediction of medicines using LVQ methodology," 2017 International Conference on Energy, Communication, Data Analytics and Soft Computing (ICECDS), Chennai, pp. 388-391, 2017.

[16] J. Amezcua, et al., "A new classification method based on LVQ neural networks and Fuzzy Logic," 2015 Annual Conference of the North American Fuzzy Information Processing Society (NAFIPS) held jointly with 2015 5th World Conference on Soft Computing (WConSC), Redmond, WA, 2015, pp. 1-5.

[17] E. Haerani, et al., "Application of unsupervised K Nearest Neighbor (UNN) and Learning Vector Quantization (LVQ) methods in predicting Rupiah to Dollar," 2016 4th International Conference on Cyber and IT Service Management, Bandung, 2016, pp. 1-4.

[18] M. Sardogan, et al., "Plant Leaf Disease Detection and Classification Based on CNN with LVQ Algorithm," 2018 3rd International Conference on Computer Science and Engineering (UBMK), Sarajevo, 2018, pp. 382-385.

[19] F. Yan, et al., "LVQ Neural Network approach for fault location of distribution network," 2011 International Conference on Electrical and Control Engineering, Yichang, 2011, pp. 237-240.

[20] X. Li and Y. Zhang, "Digital image edge detection based on LVQ neural network," 2016 IEEE 11th Conference on Industrial Electronics and Applications (ICIEA), Hefei, 2016, pp. 1251-1255.

[21] P. Sharma and S. Ugale, "Electronic tongue based liquid identification using LVQ algorithm," 2015 International Conference on Computer, Communication and Control (IC4), Indore, 2015, pp. 1-6.

[22] Jopri M. H., et al., "An Accurate Classification Method of Harmonic Signals in Power Distribution System by Utilising S-Transform," TELKOMNIKA Telecommunication Computing Electronics and Control, vol. 15(1), pp. 62-70, 2017.

[23] Habban, et al., "An Evaluation of linear time frequency distribution Analysis for VSI switch faults identification," International Journal of Power Electronics and Drive Systems (IJPEDS), vol. 8(1), pp. 1-9, 2017.

[24] A. R. Abdullah, et al., "Localization of Multiple Harmonic Sources for Inverter Loads Utilizing Periodogram," Journal of Telecommunication, Electronic and Computer Engineering (JTEC), vol. 8, pp. 87-91, 2016.

[25] T. Sutikno, et al., "Detection of Ship Image Processing and Neural Network," TELKOMNIKA Telecommunication Computing Electronics and Control, vol. 16(1), pp. 259-264, 2018.

[26] T. Sutikno, et al., "Classification of Motorcyclists not Wear Helmet on Digital Image with Backpropagation Neural Network," TELKOMNIKA Telecommunication Computing Electronics and Control, vol. 14(3), pp. 1128-33, 2016. 